\title{
Identification of ion-channel modulators that protect against aminoglycoside- induced hair cell death
}

\author{
Emma J. Kenyon, ${ }^{1}$ Nerissa K. Kirkwood, ${ }^{1}$ Siân R. Kitcher, ${ }^{1}$ Molly O’Reilly, ${ }^{1}$ Marco Derudas, ${ }^{2}$ \\ Daire M. Cantillon, ${ }^{3}$ Richard J. Goodyear, ${ }^{1}$ Abigail Secker, ${ }^{1}$ Sarah Baxendale, ${ }^{4}$ James C. Bull, ${ }^{5}$ \\ Simon J. Waddell, ${ }^{3}$ Tanya T. Whitfield, ${ }^{4}$ Simon E. Ward, ${ }^{2,6}$ Corné J. Kros, ${ }^{1}$ and Guy P. Richardson ${ }^{1}$ \\ 'Sussex Neuroscience, School of Life Sciences, ${ }^{2}$ Sussex Drug Discovery Centre, School of Life Sciences, and ${ }^{3}$ Wellcome Trust \\ Centre for Global Health Research, Brighton and Sussex Medical School, University of Sussex, Brighton, United Kingdom. \\ ${ }^{4}$ Bateson Centre and Department of Biomedical Science, University of Sheffield, Sheffield, United Kingdom. ${ }^{5}$ Department \\ of Biosciences, College of Science, Swansea University, Swansea, United Kingdom. ${ }^{6}$ Medicines Discovery Institute, Cardiff \\ University, Cardiff, United Kingdom.
}

Aminoglycoside antibiotics are used to treat life-threatening bacterial infections but can cause deafness due to hair cell death in the inner ear. Compounds have been described that protect zebrafish lateral line hair cells from aminoglycosides, but few are effective in the cochlea. As the aminoglycosides interact with several ion channels, including the mechanoelectrical transducer (MET) channels by which they can enter hair cells, we screened 160 ion-channel modulators, seeking compounds that protect cochlear outer hair cells (OHCs) from aminoglycoside-induced death in vitro. Using zebrafish, 72 compounds were identified that either reduced loading of the MET-channel blocker FM 1-43FX, decreased Texas red-conjugated neomycin labeling, or reduced neomycin-induced hair cell death. After testing these 72 compounds, and 6 structurally similar compounds that failed in zebrafish, 13 were found that protected against gentamicin-induced death of OHCs in mouse cochlear cultures, 6 of which are permeant blockers of the hair cell MET channel. None of these compounds abrogated aminoglycoside antibacterial efficacy. By selecting those without adverse effects at high concentrations, 5 emerged as leads for developing pharmaceutical otoprotectants to alleviate an increasing clinical problem.

Conflict of interest: The authors have declared that no conflict of interest exists.

License: This work is licensed under the Creative Commons Attribution 4.0 International License. To view a copy of this license, visit http:// creativecommons.org/licenses/by/4.0/

Submitted: August 9, 2017 Accepted: November 15, 2017 Published: December 21, 2017

\section{Reference information:} JCI Insight. 2017;2(24):e96773. https://doi.org/10.1172/jci. insight.96773.

\section{Introduction}

Aminoglycoside antibiotics are invaluable therapeutic agents, but they can cause deafness and, in some instances, balance disorders, largely due to the loss of hair cells from the inner ear $(1,2)$. Due to their broad spectrum and rapid bactericidal activity, they are indicated as part of empirical therapy for evident or suspected sepsis and other serious infections $(3,4)$. A major use is in pediatrics, with approximately $80 \%$ of newborns admitted to neonatal intensive care units being treated with aminoglycosides $(5,6)$. Their use is also increasing due to emerging multidrug-resistant pathogens, e.g., in the treatment of cystic fibrosis and tuberculosis $(3,7)$. The long-term daily administration of aminoglycosides required to manage these conditions results in a high incidence of hearing loss, affecting the quality of life $(8,9)$.

Hair cells have a mechanosensory hair bundle located at their apical surface, and there is evidence that the aminoglycosides, known to be permeant blockers of the mechanoelectrical transducer (MET) channels in the hair bundle, enter into hair cells via these large-conductance cation channels (10-14). Once inside the hair cell, the aminoglycosides cause increases in reactive free radicals and mitochondrial calcium concentration, leading to either apoptosis or necrosis $(1,2,15)$. While there are many points at which aminoglycoside-induced hair cell death could be prevented, blocking ototoxin entry into hair cells may be the most effective strategy for protection $(10,16)$.

Recent studies (16-23) have shown that the lateral line system of zebrafish larvae is a powerful model for discovering compounds that can protect sensory hair cells from the toxic side effects of aminoglycoside antibiotics. At least 24 compounds have been described that protect zebrafish lateral line hair cells, some of which $(16,20,23)$ reduce or block the uptake of Texas red-conjugated gentamicin (GTTR) into 
the neuromast hair cells, while others $(16,19)$ block the uptake of both GTTR and FM 1-43, a styryl dye that, like the aminoglycoside antibiotics, acts as a permeant blocker of the hair cell MET channel (24).

Thus far, however, only 4 compounds discovered using zebrafish larvae have been reported to protect hair cells of the mammalian inner ear from aminoglycoside antibiotics $(21,25,26)$. Two of these, tacrine and PROTO1, provide protection against aminoglycoside-induced hair cell death in cultures of the utricular maculae of 3- to 6-week-old mice $(16,21)$. Phenoxybenzamine (25) and berbamine have been shown, respectively, to cause partial and full protection of OHCs in mouse cochlear cultures against aminoglycosides when used at a low concentration. At slightly higher concentrations, however, both can cause OHC death $(25,26)$.

We therefore sought to identify compounds that would protect mammalian OHCs from aminoglycosides and not, either alone or in combination with the antibiotic, cause hair cell death or damage. As the hair cell MET channel can be blocked by a variety of compounds that also block other ion channels (27), a library of 160 known ion-channel agonists/antagonists (Tocriscreen Custom Collection Ion Channel Set) was screened on zebrafish larvae using 3 different assays, seeking compounds that would either block FM 1-43FX dye loading, inhibit Texas red-conjugated neomycin (TR-Neo) labeling, or prevent neomycin-induced death of hair cells. Compounds effective in any of these 3 assays, together with a small set of structurally similar compounds from the library, were then tested in mouse cochlear cultures, screening for those that protect basal-coil mammalian OHCs from gentamicin, a widely used, clinically relevant aminoglycoside antibiotic.

\section{Results}

Preselecting potential otoprotective compounds using zebrafish lateral line neuromasts. Three different screens of the Tocriscreen library were performed on zebrafish larvae at 4 days postfertilization (dpf), a stage that ensures reliable loading of both FM 1-43FX and Yo-Pro-1 into the hair cells of lateral line neuromasts $(28,29)$. In the first screen, the compounds were tested at a concentration of $100 \mu \mathrm{M}$ to determine if they would block or reduce the loading of $3 \mu \mathrm{M}$ FM 1-43FX (Figure 1, A-D, and Supplemental Figure 1, A and B; supplemental material available online with this article; https://doi.org/10.1172/jci.insight.96773DS1). In the second screen, compounds were assessed at a concentration of $100 \mu \mathrm{M}$ for their ability to reduce the entry of $25 \mu \mathrm{M}$ TR-Neo into hair cells (Figure 1E and Supplemental Figure 1, C and D). In the third screen, the compounds were tested at a concentration of $25 \mu \mathrm{M}$ for their ability to protect hair cells prelabeled with Yo-Pro-1 from damage or death caused by exposure to $6.25 \mu \mathrm{M}$ neomycin for 1 hour (Figure 1F and Supplemental Figure 1, E-H). Each screen was repeated on 3 independent occasions.

The FM 1-43FX screen identified 37 compounds that showed full or partial block of dye loading (Figure 1D), the TR-Neo screen identified 53 compounds that showed complete block or reduction of labeling (Figure 1E), and the neomycin-protection screen identified 43 compounds that either partially or fully protected hair cells (Figure 1F). One of the compounds, suramin, provided a positive result in all 3 screens but is known to be promiscuous in biological assays (30) and was therefore excluded from the results described above and further consideration. One compound, 13228, consistently killed the larvae during the neomycin-protection assay, and it was therefore not possible to assess its potential protective ability. Slowed circulation was also detected with this compound in the FM 1-43FX and TR-Neo assays. In total, 72 compounds were positive in 1 of the 3 assays on at least one trial, and 19 of these were effective in all 3 assays, reducing FM 1-43FX loading, TR-Neo entry, and neomycin-induced cell death.

Retesting compounds from zebrafish screens in mouse cochlear cultures. The 72 compounds identified above, along with an additional 6 structurally similar compounds from the library that were negative in all 3 zebrafish assays, were initially tested in a single trial at a concentration of $50 \mu \mathrm{M}$ in mouse cochlear cultures to see if they would protect hair cells from exposure to $5 \mu \mathrm{M}$ gentamicin for 48 hours, a concentration of gentamicin sufficient to kill hair cells in the basal third of the cochlea. Compounds that were generally cytotoxic or failed to provide any evidence of protection at this step were not pursued further. Those that improved basal-coil OHC survival in the presence of gentamicin were subsequently retested on two or more independent occasions, with the numbers of individual cochleae used for each compound ranging from 3 to 11 . Using this approach, and the criteria described in the Supplemental Methods, 12 protective compounds (including 1 of the 6 selected on the basis of structural similarity to those that were effective in the zebrafish) and 1 partially protective compound were identified (Figure 2, Supplemental Table 1, and Supplemental Figure 2). When the concentration was reduced to $10 \mu \mathrm{M}, 3$ of the 13 compounds (13097, 13143 , and 13170) were protective, 6 were partially protective, and 4 provided no protection (Supplemental Table 1 and Supplemental Figures 2 and 3). 


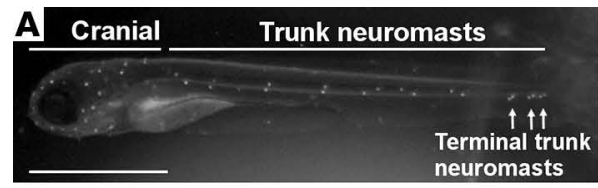

D
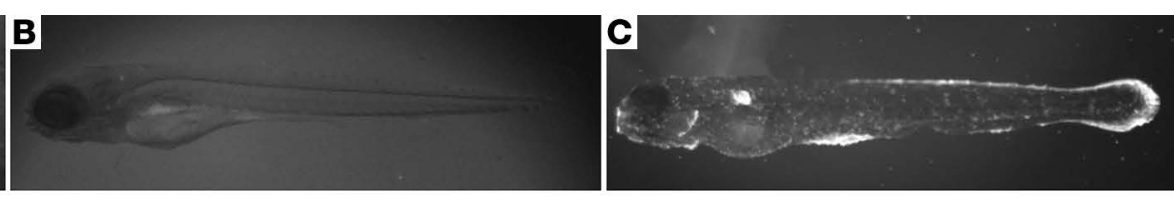

FM 1-43FX screen

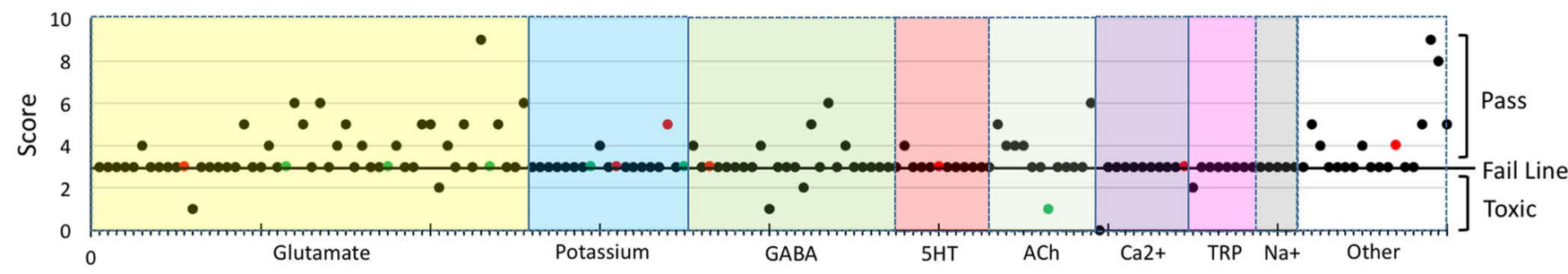

$\mathbf{E}$

TR-Neo screen

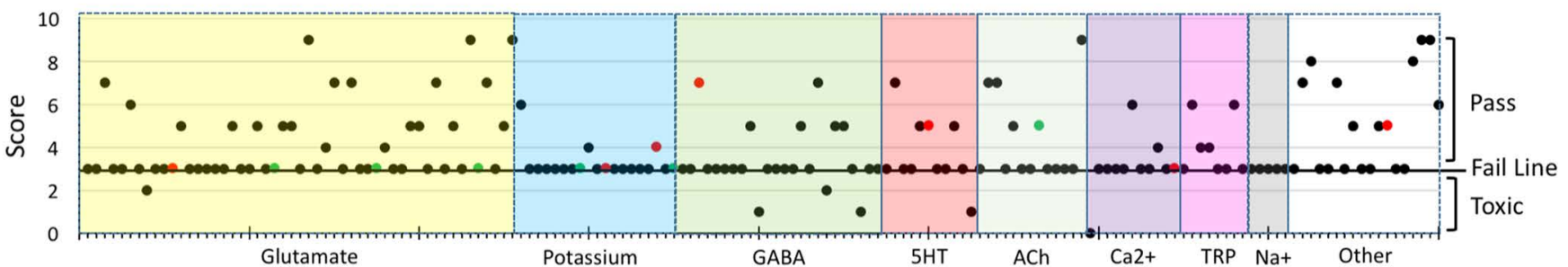

$\mathbf{F}$

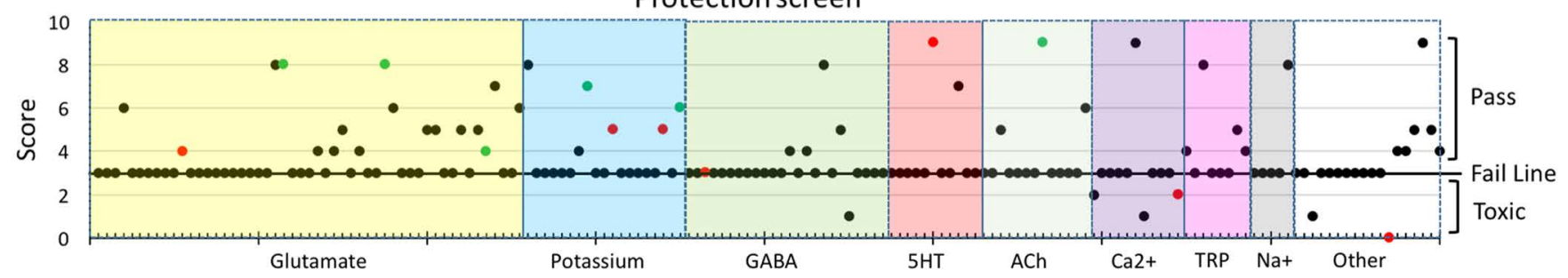

Figure 1. Zebrafish screen. (A) Cranial and trunk neuromasts in a control larva treated with FM 1-43FX and imaged with the Phenosight system, (B) a larva in which the compound blocked FM 1-43FX entry into hair cells, and (C) a larva that became fluorescent in which neuromasts could not be screened. (D-F) Scatter plots showing all results for each screen. Compounds are grouped according to biological activity. Compounds were given a score where 0 = toxic, $1=$ no block or no protection, $2=$ weak block or partial protection, and $3=$ full protection. Each screen was repeated 3 times so the pass threshold is $>3$ (at least 1 screen with a score higher than 1), fail = 3 ( 3 screens each with a score of 1 ), and toxic $<3$. Colored dots identify compounds that protected hair cells in mouse cochlear cultures from gentamicin: green dots identify those that blocked the MET channel, and red dots identify those that did not block the MET channel. All larvae were at $4 \mathrm{dpf}$. Scale bar: $1 \mathrm{~mm}$.

With 8 of these 13 compounds that provided protection at $50 \mu \mathrm{M}(13087,13104,13142,13150,13170$, 13190,13196 , and 13228) varying degrees of hair-bundle damage were observed in the presence of gentamicin (Figure 2). To determine if any had adverse effects on hair cells in the absence of gentamicin, they were tested alone at concentrations of 50 and $100 \mu \mathrm{M}$ (Figure 3 and Supplemental Figure 4). At $50 \mu \mathrm{M}, 5$ compounds (13087, 13150, 13170, 13196, and 13228) caused hair-bundle damage (Supplemental Figure 4, $\mathrm{B}, \mathrm{G}, \mathrm{I}, \mathrm{K}$, and $\mathrm{N})$. When the concentration was increased to $100 \mu \mathrm{M}, 4$ compounds $(13087,13150,13218$, and 13228) were generally cytotoxic or caused loss of the sensory epithelium (Figure 3, B, G, L, and N), and a further 4 compounds (13104, 13170, 13190, and 13196) caused hair-bundle damage (Figure 3, D and I-K). Of the 13 compounds, only 5 (13097, 13142, 13143, 13154, and 13222) did not cause hair cell death or hair-bundle damage at a concentration of $100 \mu \mathrm{M}$.

Two of the compounds, 13097 and 13143, those that did not cause hair-bundle damage when tested alone at $100 \mu \mathrm{M}$ and also provided protection against $5 \mu \mathrm{M}$ gentamicin at a concentration of $10 \mu \mathrm{M}$, were subsequently tested to determine the minimum concentration at which they would protect against $5 \mu \mathrm{M}$ 

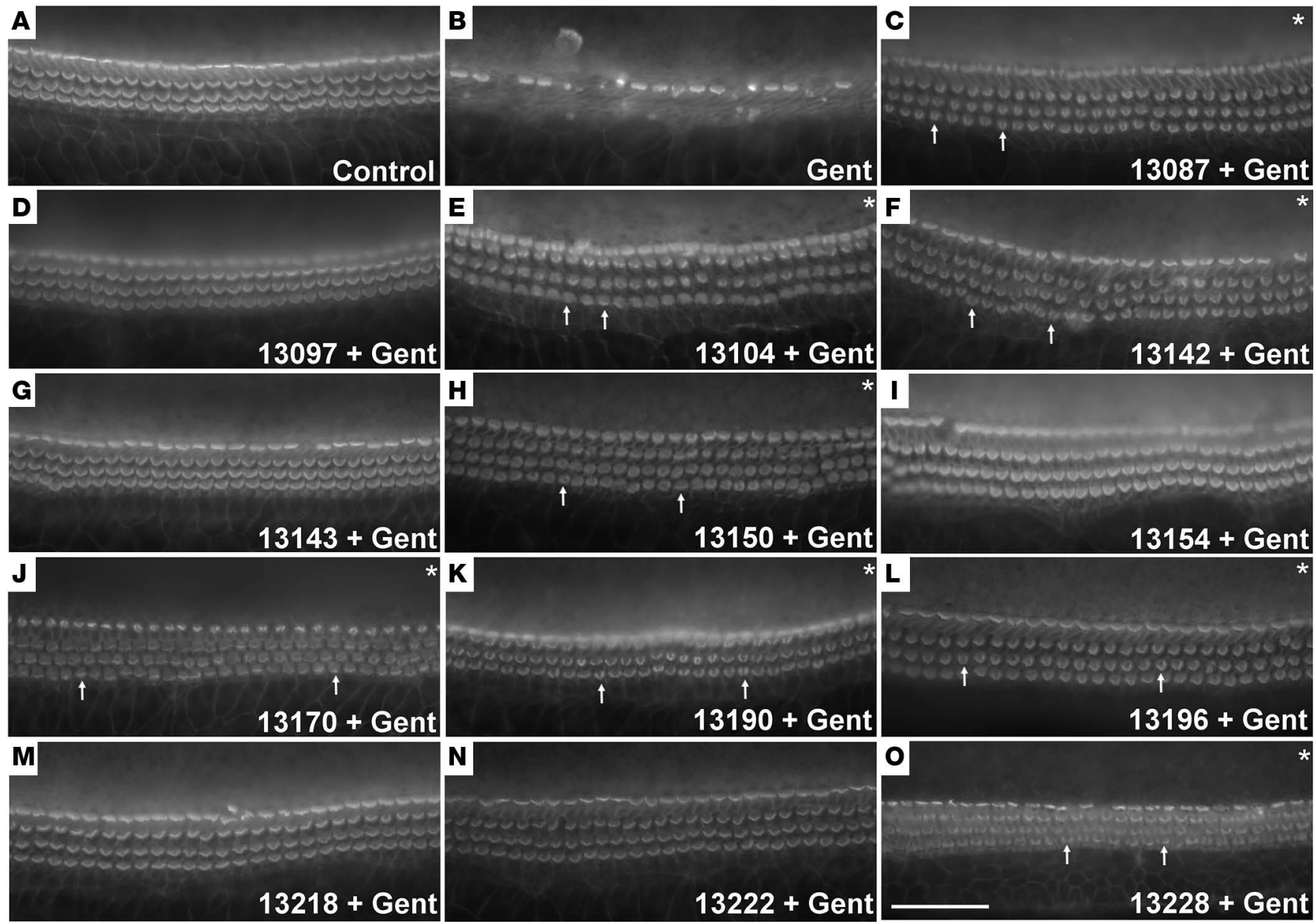

Figure 2. Compounds providing protection against gentamicin-induced hair cell loss in mouse cochlear cultures. Cochlear cultures from $\mathrm{P} 2$ pups were treated with either (A) $0.5 \%$ DMSO ( $n=67)$, (B) $5 \mu$ M gentamicin and $0.5 \%$ DMSO $(n=67)$, or (C-0) $5 \mu$ M gentamicin and $50 \mu \mathrm{M}$ compound (C)

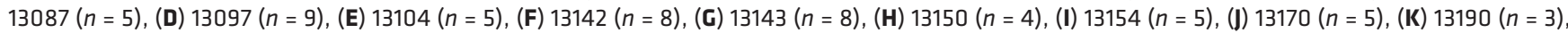
(L) $13196(n=5),(\mathbf{M}) 13218(n=10),(\mathbf{N}) 13222(n=11)$ and $(\mathbf{O}) 13228(n=4)$. Cultures were labeled with TRITC-phalloidin, and images were acquired from the basal coil. Images in $\mathbf{A}$ and $\mathbf{B}$ are representative of 67 experiments. Images in $\mathbf{C}-\mathbf{0}$ are representative of $4-11$ experiments. A compound was considered protective if it protected in $\geq 60 \%$ of tests. Asterisks identify cultures with damaged hair bundles; arrows indicate specific examples of some of the damaged bundles. Scale bar: $50 \mu \mathrm{m}$.

gentamicin (Figure 4 and Supplemental Table 1). Compound 13143 provided protection down to $1 \mu \mathrm{M}$ (half-protecting concentration $K=840 \mathrm{nM}$ ) with a $95 \%$ CI of $210-1,480 \mathrm{nM}$, and compound 13097 was effective at concentrations as low as $10 \mathrm{nM}$, with $K=4.9 \mathrm{nM}$ (95\% CI $2.2-7.7 \mathrm{nM})$.

Effects of otoprotective compounds on MET-channel currents in mouse OHCs. To determine if any of the 13 compounds that prevented gentamicin-induced hair cell death in cochlear cultures impede antibiotic entry via the MET channel, we tested whether they block MET currents in OHCs. Each compound was tested at a concentration of $50 \mu \mathrm{M}$ at membrane potentials ranging from $-164 \mathrm{mV}$ to $+96 \mathrm{mV}$. Examples of MET currents recorded before, during, and after exposure to $50 \mu \mathrm{M}$ of 13143 or 13222 are shown in Figure 5, $\mathrm{A}$ and $\mathrm{B}$, respectively. MET currents were unaffected during superfusion with 13143 but were reduced in amplitude by 13222 . This reduction in MET current amplitude caused by 13222 was observed at all potentials tested $(-164 \mathrm{mV}$ to $+96 \mathrm{mV})$ and was strongest at moderately negative membrane potentials. Current-voltage curves derived from the peak MET currents recorded at all membrane potentials before, during, and after compound exposure further revealed the lack of interaction of 13143 with the channel (Figure 5C) and the voltage-dependence of the channel block by 13222 (Figure 5D). The MET currents and current-voltage curves also demonstrated that the currents fully recovered following 13222 exposure, indicating that the channel block was completely reversible. Of the 13 compounds tested, 7 had no effect on the MET current size across all membrane potentials, indicating a lack of interaction with the channel 

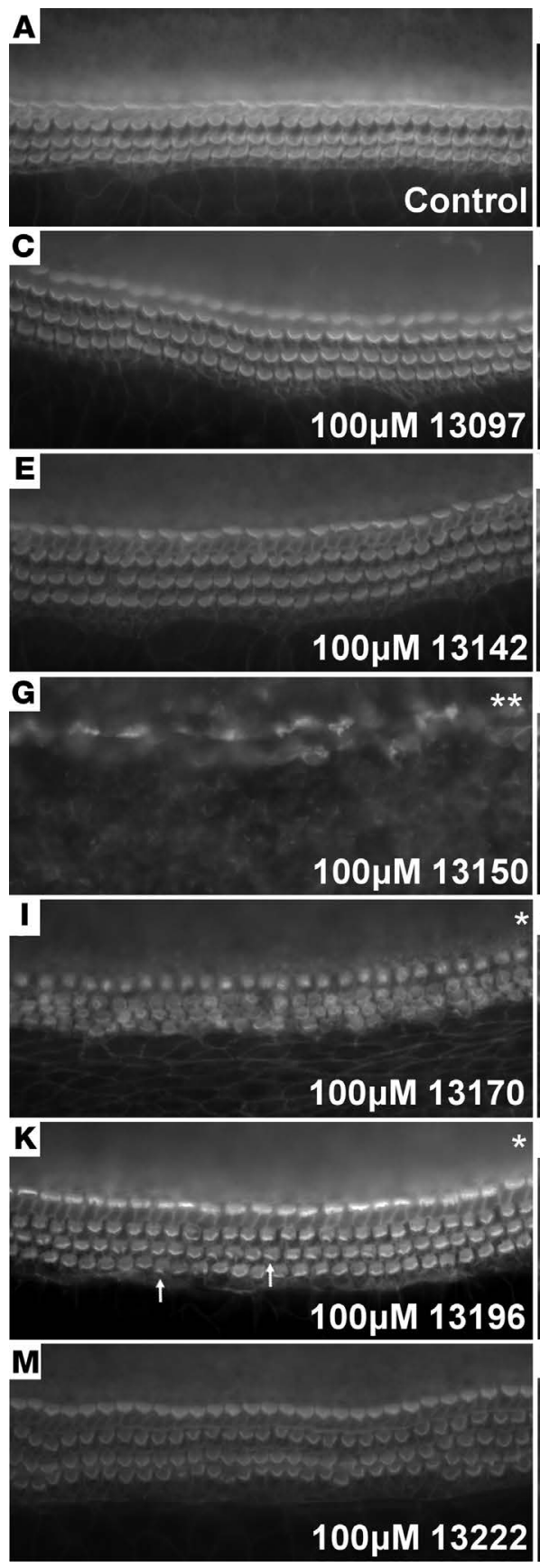
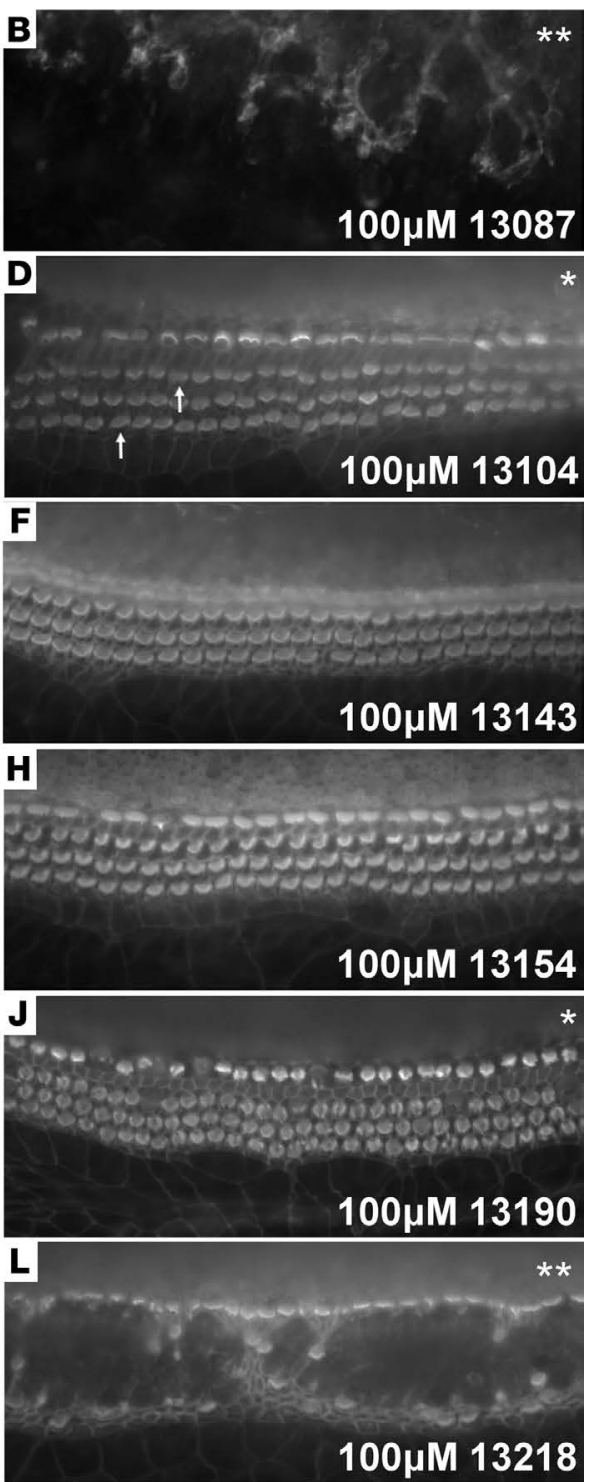

$\mathrm{N}$

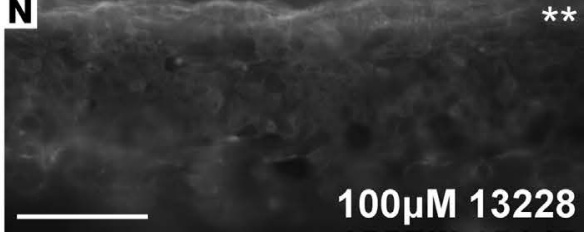

Figure 3. Effects of compounds $(100 \mu \mathrm{M})$ on mouse cochlear hair cells in the absence of gentamicin. Cultures from P2 pups were treated for 48 hours with either (A) 1\% DMSO ( $n=2)$ or (B-N) $100 \mu \mathrm{M}$ compound as indicated $(n=2$ for all compounds). Cultures were labeled with TRITC-phalloidin, and images were acquired from the basal coil. Asterisks identify compounds that damage hair bundles, with arrows indicating examples of damaged bundles. Double asterisks identify compounds that were cytotoxic or caused loss of the sensory epithelium. Scale bar: $50 \mu \mathrm{m}$.

(Figure 5E and Supplemental Table 1). Six of the thirteen compounds (13087, 13104, 13142, 13154, 13218, and 13222) interacted with the MET channel. All but one of these (13087) provided a maximum block at moderately negative membrane potentials (e.g., at $-44 \mathrm{mV}$ for 13222) and a partial release of the block at both extreme negative and positive potentials (Figure $5 \mathrm{~F}$ and Supplemental Table 1). The partial release of the block at negative potentials reveals that the compounds are, like dihydrostreptomycin (13) and FM 1-43 (24), permeant blockers of the MET channel.

Effects of otoprotective compounds on $\mathrm{K}^{+}$-channel currents in mouse OHCs. Of the 13 compounds that protect mouse OHCs from gentamicin-induced death, $4(13087,13097,13143$, and 13154) are potassium channel blockers (31-34). Two of these are blockers of $\mathrm{K}_{\mathrm{V}} 7$ channels (13097 and 13143), but they do not block the MET channel. We therefore tested whether any of the 13 compounds blocked the slow outward $\mathrm{K}^{+}$current $\left(I_{\mathrm{K}, \text { neo }}\right)$ that is expressed by early postnatal mouse OHCs and activates at potentials positive to $-50 \mathrm{mV}$ (35). OHCs were exposed to $30 \mu \mathrm{M}$ of each compound, and currents were elicited by applying a series of 

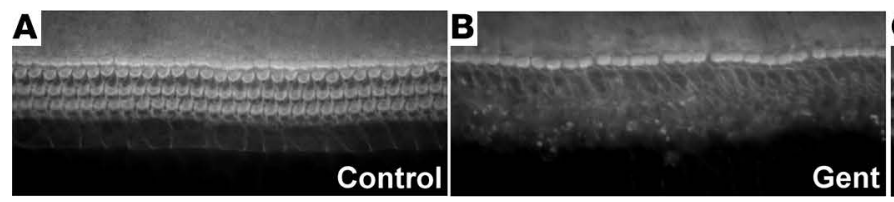

$\mathbf{K}$

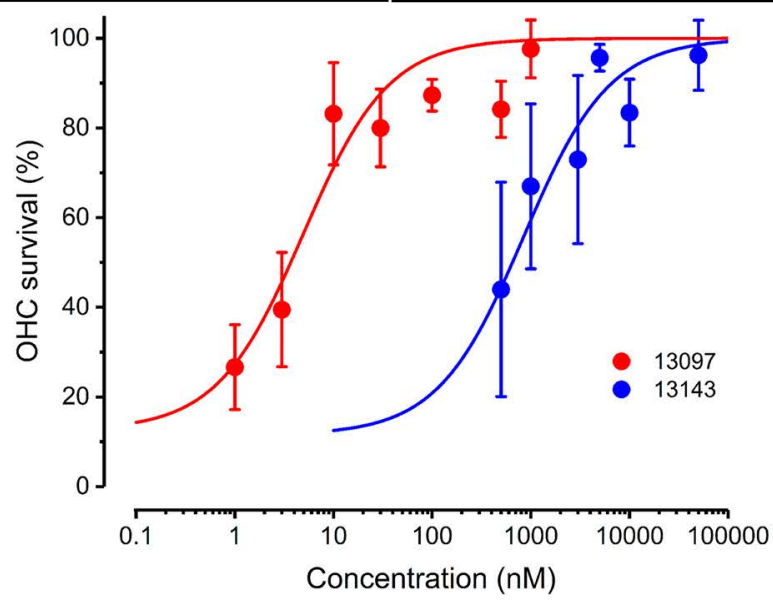

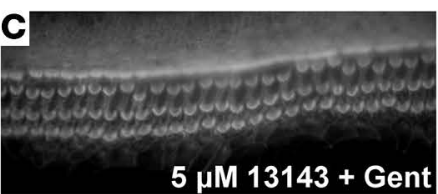
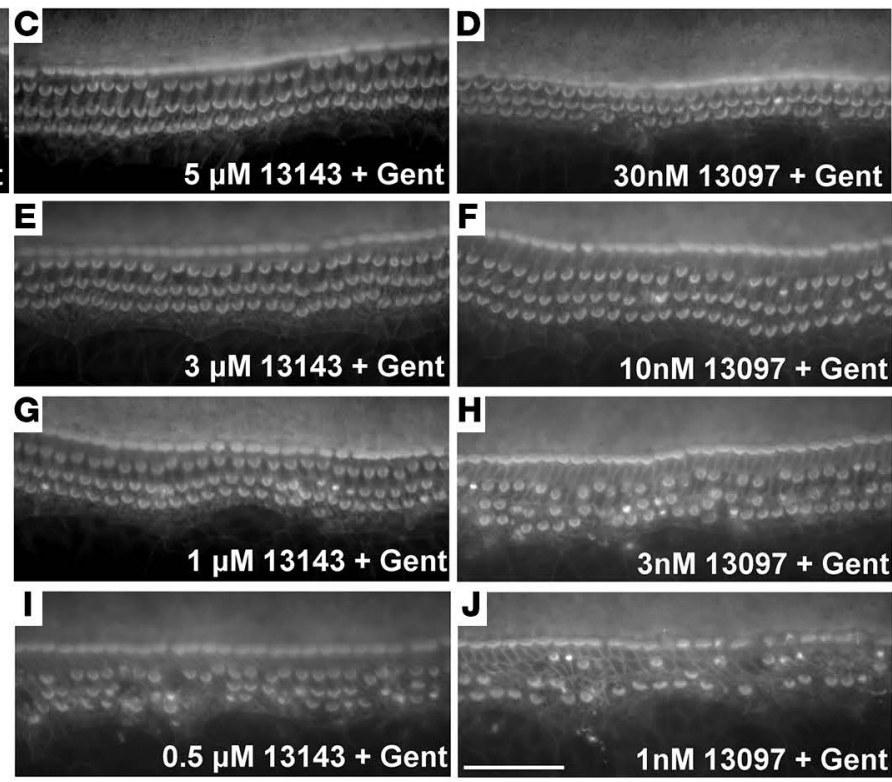
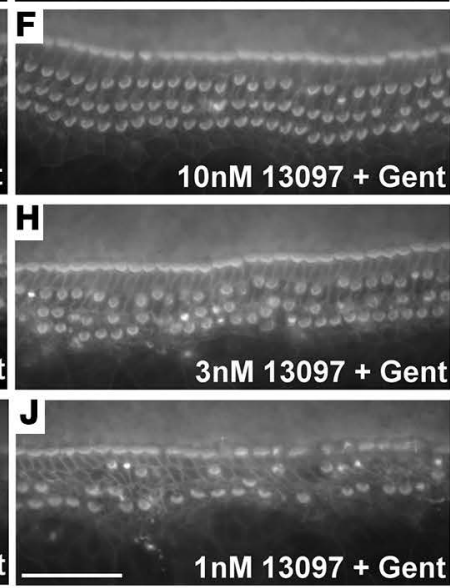

Figure 4. Compounds providing protection against $\mathbf{5} \boldsymbol{\mu} \mathbf{M}$ gentamicin at low concentrations. Cultures prepared from $\mathrm{P} 2$ pups were treated with (A) 0.5\% DMSO ( $n=67)$, (B) $5 \mu \mathrm{M}$ gentamicin $(n=67), 5 \mu \mathrm{M}$ gentamicin and 13143 at (C) $5 \mu \mathrm{M}(n=5),(\mathbf{E}) 3 \mu \mathrm{M}(n=5),(\mathbf{G}) 1 \mu \mathrm{M}(n=4)$, and (I) $0.5 \mu \mathrm{M}(n=$ 3) or $5 \mu$ M gentamicin and 13097 at (D) $30 \mathrm{nM}(n=5),(\mathbf{F}) 10 \mathrm{nM}(n=5),(\mathbf{H}) 3 \mathrm{nM}(n=4)$, and (J) 1 nM ( $n=4)$ (numbers of independent tests are shown after each compound number). Cultures were labeled with TRITC-phalloidin. Images in A and B are representative of 67 experiments. Images in C-J are representative of 3-5 experiments. (K) Dose-response curves showing the percentage survival of basal-coil OHCs in cultures treated with gentamicin and either compound 13097 (red) or compound 13143 (blue) compared with that in control cultures. Error bars are SEM from 3-8 independent tests. Curves are fit to the equation: OHC survival $(\%)=B+(100-B)[C] /(K+[C])$, where $B$ is the percentage of OHCs surviving in gentamicin alone, $[C]$ is the concentration of the compound, and $K$ is the compound concentration at which $50 \%$ protection occurs. For $13097, K=4.9$ nM and $B=12.6 \%$; for 13143 , $K=840 \mathrm{nM}$ and $B=11.5 \%$. Scale bar: $50 \mu \mathrm{m}$.

hyperpolarizing and depolarizing voltage steps from a holding potential of $-84 \mathrm{mV}$ (Figure 6). Examples of currents recorded before, during, and after application of 3 of the compounds, the $\mathrm{K}_{\mathrm{v}} 7$ blockers 13097 and 13143, and 13142, a compound that also blocked the MET channel, are shown in Figure 6, A, C, and E, along with the activation curves derived from the tail currents recorded before and during exposure (Figure $6, \mathrm{~B}, \mathrm{D}$, and F). The average reduction in the maximum conductance $\left(G_{\max }\right)$ of $I_{\mathrm{K}, \text { neo }}$ caused by each compound and the distribution of data are shown in Supplemental Table 2 and Figure 6G, respectively. Of the 13 compounds tested, only two (13170 and 13196) had no effect on $I_{\mathrm{K}, \text { neo }}$ at a concentration $30 \mu \mathrm{M}$ (Figure 6G and Supplemental Table 2). The remaining 11 compounds, however, notably reduced $I_{\mathrm{K}, \text { neo }}$ to varying degrees; these included linopirdine (13143), a compound that has previously been reported not to block $I_{\mathrm{K}, \text { neo }}(35)$. The effects of the compounds on the half activation potential $\left(\mathrm{V}_{1 / 2}\right)$ and the voltage sensitivity of activation (S) are listed in Supplemental Table 2. Most compounds did not change $\mathrm{V}_{1 / 2}$ or $\mathrm{S}$ significantly, suggesting a homogeneous block of the ion channels underlying $I_{\mathrm{K}, \text { neo }}$.

Testing effects of compounds on the antimicrobial efficacy of gentamicin. The 13 compounds that protect $\mathrm{OHCs}$ from gentamicin-induced death were tested in a bacterial cell viability assay to identify whether any decrease the antibiotic activity of gentamicin. The minimum inhibitory concentration (MIC, defined here as the minimum concentration of gentamicin required to inhibit bacterial growth by $\geq 99 \%$ ) of gentamicin was established for 3 circulating strains of clinically relevant bacteria: Klebsiella pneumoniae, Pseudomonas aeruginosa, and Staphylococcus aureus. The bacteria were treated with gentamicin at the MIC $(2.2 \mu \mathrm{M})$ together with each compound at 5 times the gentamicin MIC $(11 \mu \mathrm{M})$. None of the compounds resulted in a decrease in gentamicin activity (Supplemental Figure 5). When the experimental grouping structure was explicitly modeled as random effects (technical replicates nested within biological replicates) using a mixed-effects model, two individual cases of significant decreases in bacterial cell survival were identified [Pseudomonas aeruginosa, compound 13170, $t_{11}=2.90, P_{\text {(FDR-adjusted) }}=0.049 ;$ Klebsiella pneumoniae, compound $13228, t_{11}=3.74, P_{\text {(FDR-adjusted) }}=0.002$, where $t_{11}$ is the degree of freedom in a $t$ distribution], but neither was found to be significant in more than one assay, and a significant decrease in bacterial cell survival was not identified in the Staphylococcus aureus assay. 

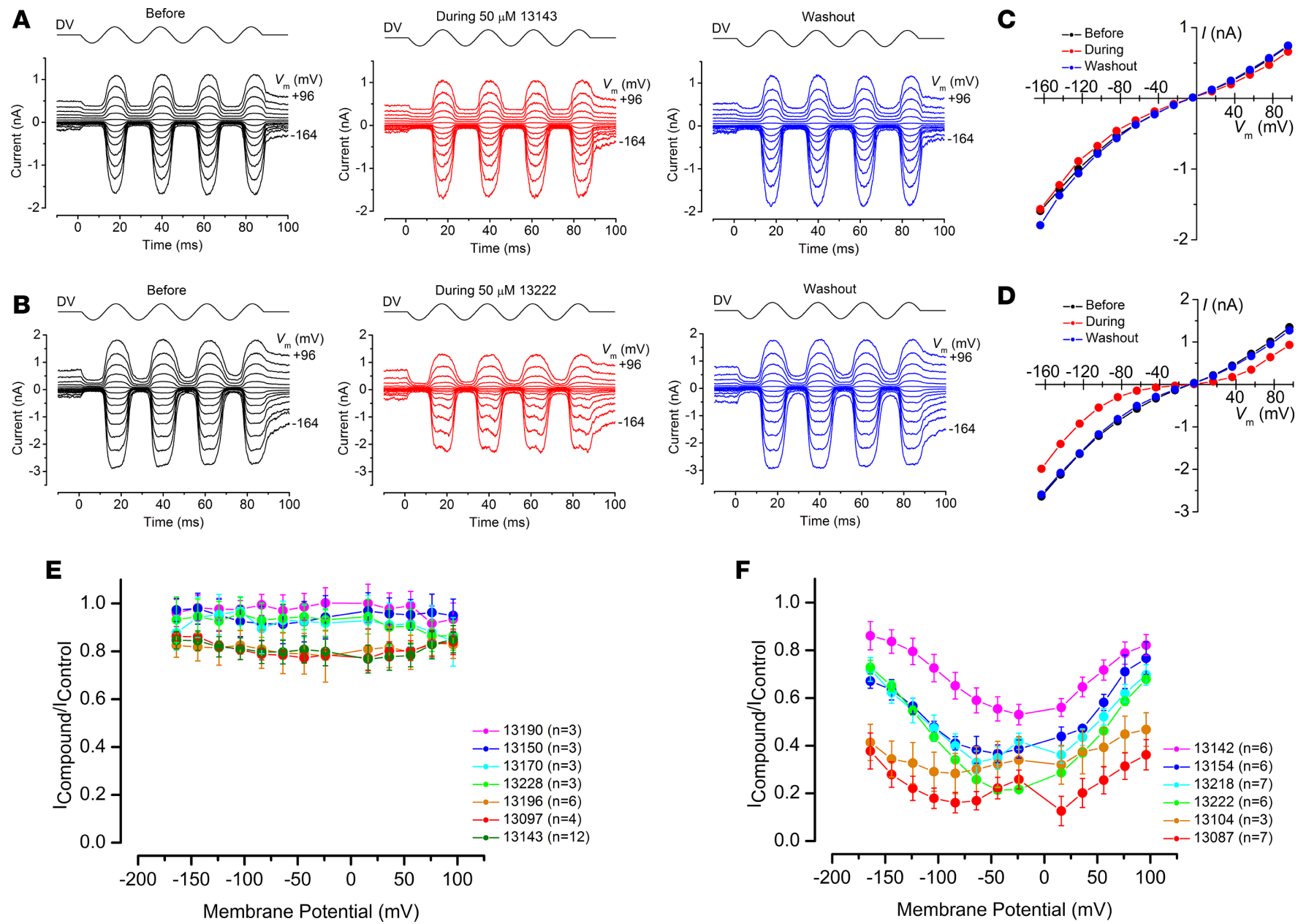

Figure 5. Interactions of otoprotectants with the MET channel. Representative MET currents from OHCs in cultures prepared from P2 pups recorded before, during, and after exposure to (A) $50 \mu \mathrm{M} 13143(n=12)$ and (B) $50 \mu \mathrm{M} 13222(n=6)$. MET currents were recorded at membrane potentials from $-164 \mathrm{mV}$ to $+96 \mathrm{mV}$ in response to a sine-wave stimulus. Current-voltage curves for the peak MET currents derived from the recordings shown in $\mathbf{A}$ and B demonstrate (C) the lack of interaction of 13143 with the channel and (D) the voltage-dependence of block by 13222. (E) Fractional block of the MET currents at all membrane potentials reveals that 7 compounds, including 13143, do not interact with the channel. (F) Six compounds, including 13222, provide a voltage-dependent block that is in most cases strongest at moderately negative potentials. Error bars are SEM. Numbers of independent tests are shown after each compound number in graphs ( $E$ and $\mathbf{F}$ ).

Candidate otoprotectants for cochlear OHCs and possible mechanisms of action. The results described above suggest that 5 compounds $(13097,13142,13143,13154$, and 13222) are candidate otoprotectants for high-frequency-encoding $\mathrm{OHCs}$, protecting against $5 \mu \mathrm{M}$ gentamicin at a concentration of $50 \mu \mathrm{M}$ (or in some cases considerably less), not causing hair cell death or hair-bundle damage when tested alone at a concentration of $100 \mu \mathrm{M}$, and not inhibiting the antimicrobial action of gentamicin. Three of these compounds (13142, 13154, and 13222) are MET channel blockers (Figure 5F and Supplemental Table 1) and may therefore prevent or reduce gentamicin entry via this route. All 5 block $I_{\mathrm{K}, \text { neo }}$ (Figure 6G and Supplemental Table 1) and could potentially depolarize the OHCs and reduce the rate of aminoglycoside loading by decreasing the driving force for entry via the MET channel.

To test whether any of the 5 candidate otoprotectants would block or reduce the accumulation of gentamicin, we exposed mouse cochlear cultures to a low concentration of GTTR in the presence of a large molar excess of each of the compounds for a short period of time. Compound 13170, a compound that blocks TR-Neo and FM 1-43FX loading in the zebrafish assays, was found to cause a considerable decrease in GTTR loading in OHCs $\left(t_{7}=9.66, P=0.0001\right.$ using mixed-effects modeling) and was used as a positive control. A significant decrease $\left(t_{7}=4.15, P=0.0043\right)$ in GTTR loading was seen in OHCs that were exposed to GTTR in the presence of 13143 but not in those exposed to GTTR in the presence of $13142\left(t_{7}=0.833, P\right.$ $=0.43), 13097\left(t_{7}=0.883, P=0.41\right), 13154\left(t_{7}=0.528, P=0.61\right)$, or $13222\left(t_{7}=1.65, P=0.14\right)$ (Figure 7). 
A

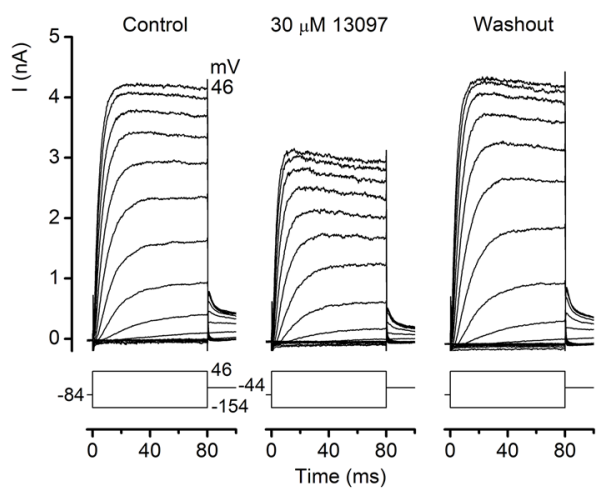

C

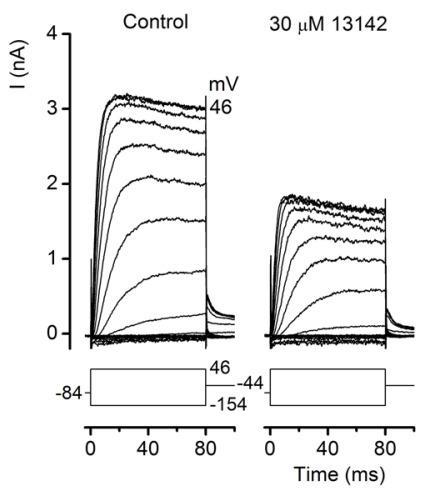

E

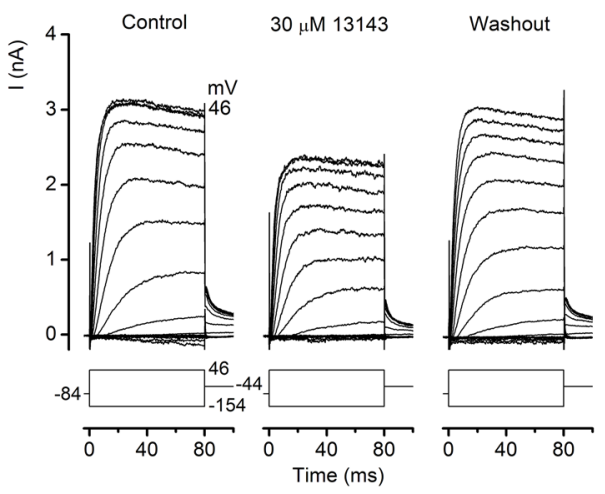

G

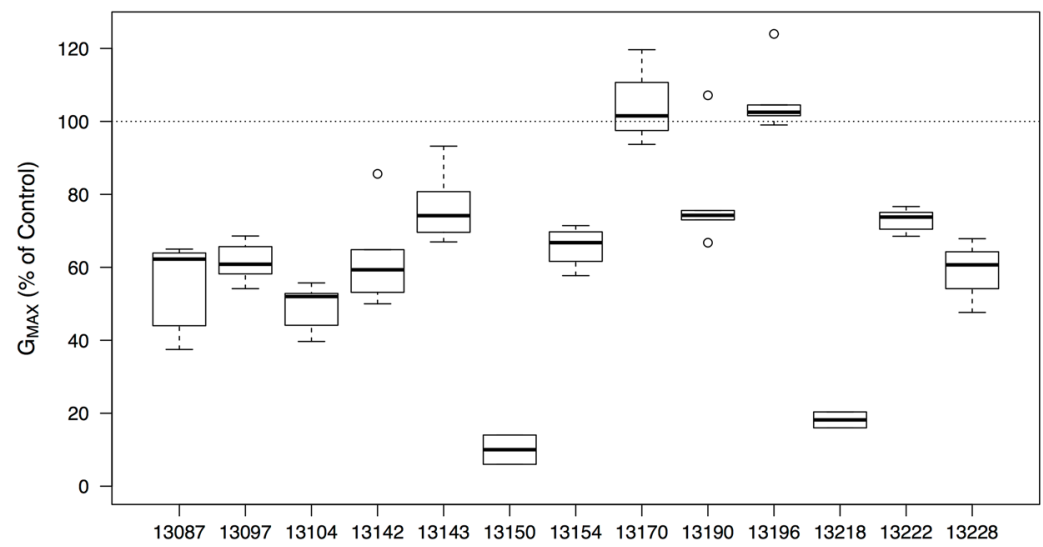

$30 \mu \mathrm{M}$ of Compound

B

D

$\mathbf{F}$

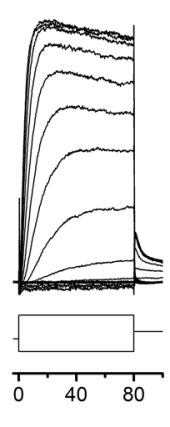

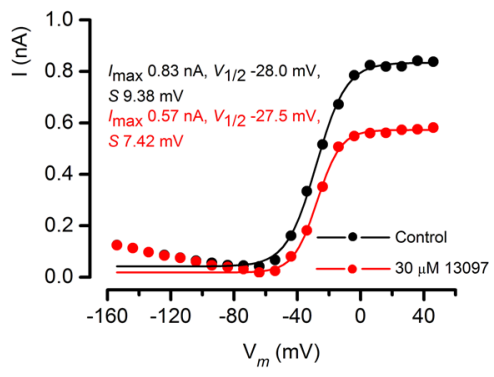
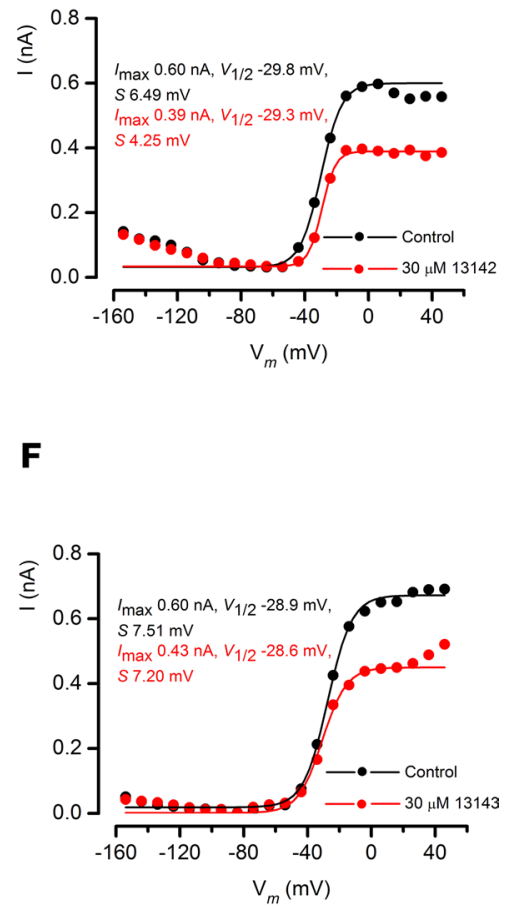

G). In cultures teated with $5 \mu \mathrm{Mgentamin}$ in the presence of an additional $18 \mathrm{mM} \mathrm{NaCl}$ (Figure $8 \mathrm{D}$ ), hair cell loss was comparable to and not significantly different from that observed with $5 \mu \mathrm{M}$ gentamicin in normal medium $(z=$ $0.12, P>0.99$ ) (Figure 8, B and G). In cultures treated with $5 \mu \mathrm{M}$ gentamicin in the presence of an additional $18 \mathrm{mM} \mathrm{KCl}$ (Figure 8F), there was a large and significant increase in hair cell numbers relative to those observed with $5 \mu \mathrm{M}$ gentamicin in normal medium $(z=10.0, P<$ 0.001) (Figure 8, B and G), although numbers were also significantly reduced relative to those observed in control medium without gentami$\operatorname{cin}(z=3.8, P=0.001)$ (Figure $8, \mathrm{~A}$ and $\mathrm{G}$ ).

Although the results above provide evidence that $\mathrm{K}^{+}$depolarization can, as expected, provide protection against aminoglycoside antibiotics, none of the 5 candidate otoprotectants $(13097,13142,13143,13154$, 

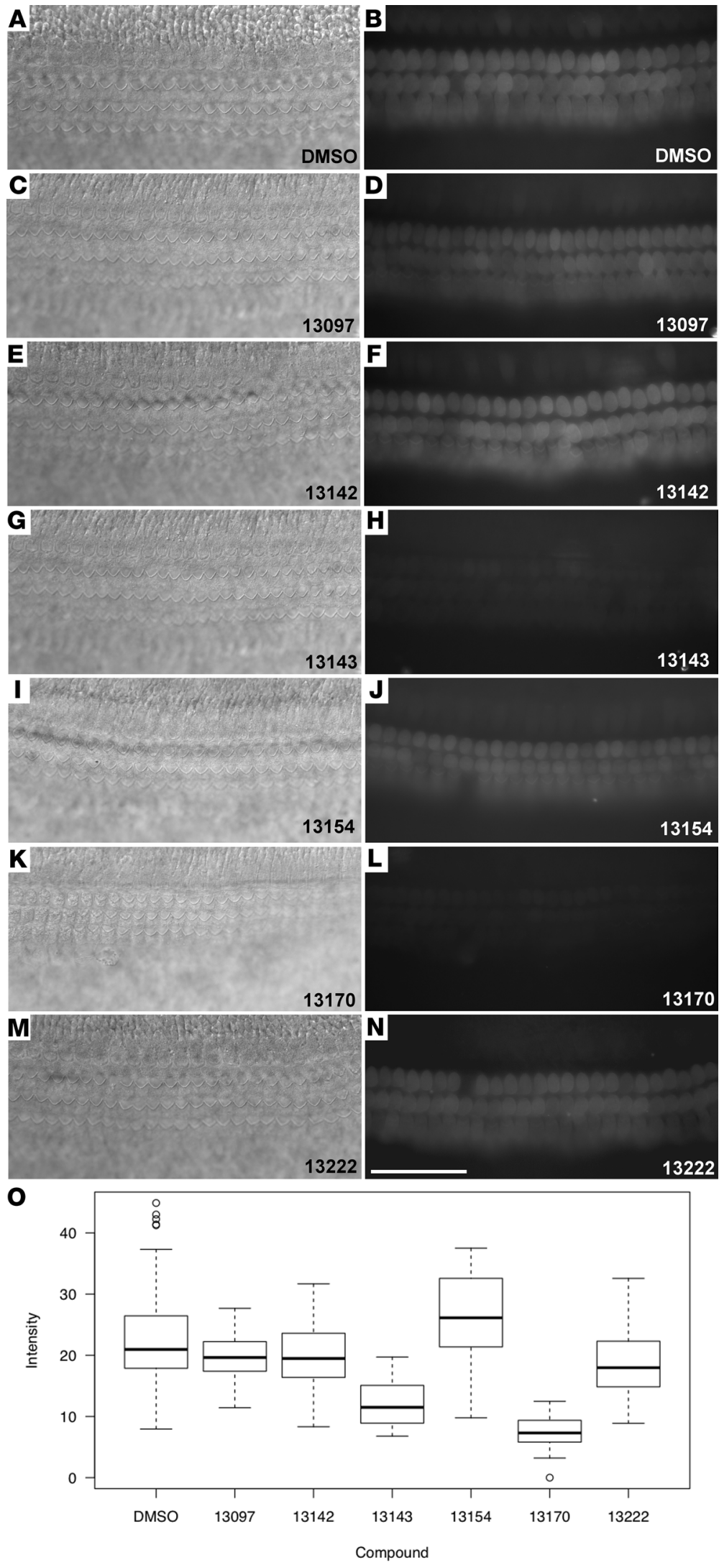
. , 13228 ) caused loss of viability, 6 compounds (13087, $13142,13154,13170,13190$, and 13196) showed partial protection (Supplemental Figure 6, C, F, G, H, I, and J), and 4 compounds (13097, 13104, 13218, and 13222 ) showed strong protection (Supplemental Figure 6, D, E, K, and L).

\section{Discussion}

Using a combination of zebrafish lateral line organs and mouse cochlear cultures as screening tools, we discovered 13 compounds that protect or provide partial protection of basal-coil mouse OHCs from gentamicin-induced cell death (Figure 10A). In the zebrafish assays, 2 of the 13 compounds reduced FM 1-43FX loading, 5 diminished TR-Neo labeling, and 10 provided protection from neomycin-induced cell death. Notably, however, only 1 of the 

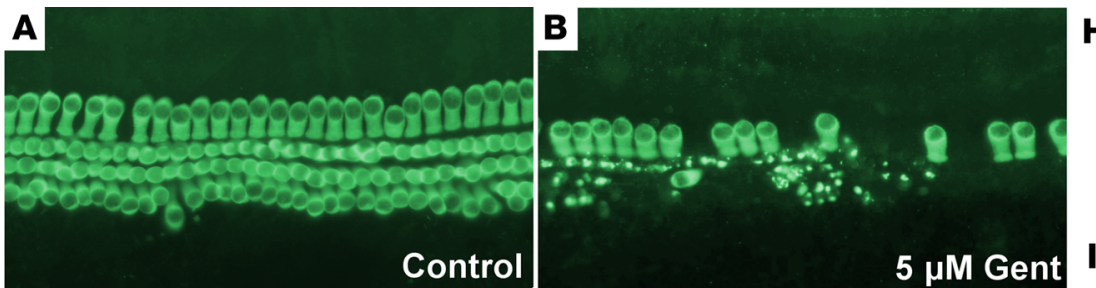

\section{H}

$30 \mu \mathrm{M} 13097$
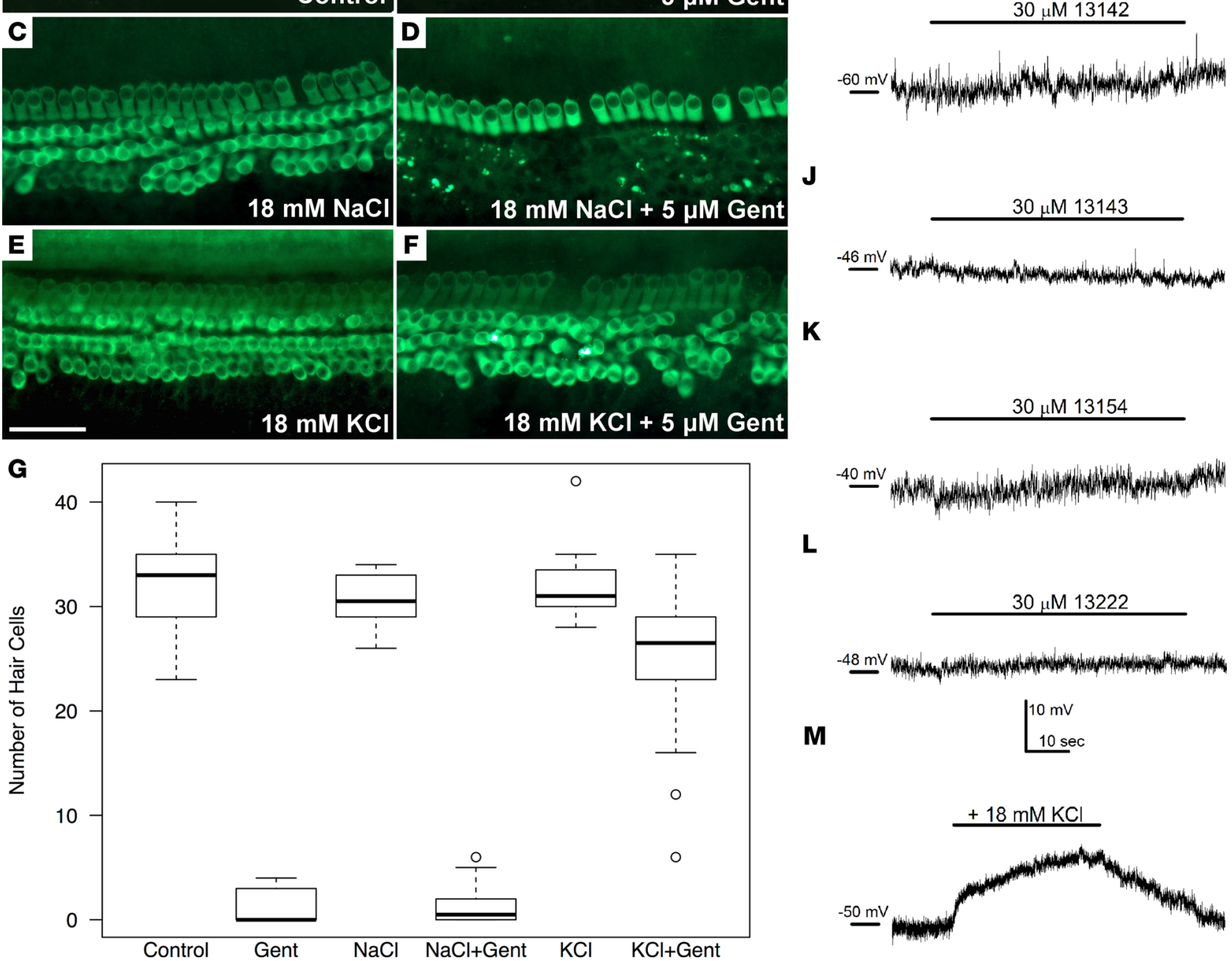

Figure 8. Effects of elevated $\mathrm{K}^{+}$and $\mathrm{Na}^{+}$and effects of lead otoprotectants on resting membrane potential. (A-F) Cochlear cultures from $\mathrm{P} 2$ pups were grown in $(\mathbf{A})$ control medium $(n=5)$ or $(\mathbf{B})$ medium containing $5 \mu \mathrm{M}$ gentamicin $(n=3),(\mathbf{C}) 18 \mathrm{mM} \mathrm{NaCl}(n=4)$, (D) $18 \mathrm{mM} \mathrm{NaCl}$ with $5 \mu \mathrm{M}$ gentamicin $(n=6)$, (E) $18 \mathrm{mM} \mathrm{KCl}(n=4)$, and $(\mathbf{F}) 18 \mathrm{mM} \mathrm{KCl}$ with $5 \mu \mathrm{M}$ gentamicin $(n=6)$. Cultures were labeled with antibodies to myosin 7 a. Scale bar: $50 \mu \mathrm{m}$. (C) Box-and-whisker plot showing numbers of $\mathrm{OHCs}$ remaining in the mid-basal region. Thick line = median; boxes = interquartile range (IQR). Whiskers extend an additional 1.5× IQR beyond the boxes. Outliers are shown as white circles. (H-M) Representative current clamp recordings of membrane potential in $\mathrm{OHCs}$ in cochlear cultures from $\mathrm{P} 2$ pups, obtained during and after superfusion with $30 \mu \mathrm{M}$ of compounds as indicated and 18 $\mathrm{mM} \mathrm{KCl}$. The addition of $18 \mathrm{mM} \mathrm{KCl}$ to the extracellular solution results in a rapid depolarization of the cell of approximately $15 \mathrm{mV}$ that is reversible upon a return to normal KCl levels $(n=10)$. Exposing the cells to the otoprotectant compounds $13097(n=10), 13142(n=5), 13143(n=11), 13154(n=7)$, and $13222(n=7)$ has no effect on the resting membrane potential.

19 compounds that was effective in all 3 zebrafish assays protected mouse OHCs from gentamicin, and 10 of the 13 compounds that were successful in mouse cochlear cultures would have been detected using the neomycin-protection assay alone. The added value of the TR-Neo-labeling and FM 1-43FX-loading assays for future large-scale screens is therefore questionable. A retrospective screen of the 13 compounds that protect mouse cochlear hair cells in zebrafish using gentamicin rather than neomycin did not identify all of the compounds, as a subset consistently caused a loss of larval viability over the longer duration required for the assay ( 5 hours for gentamicin as opposed to 1 hour for neomycin). Nonetheless, 4 of the 5 lead otoprotectants (see below) would have been identified had the gentamicin assay been used for the primary selection. 

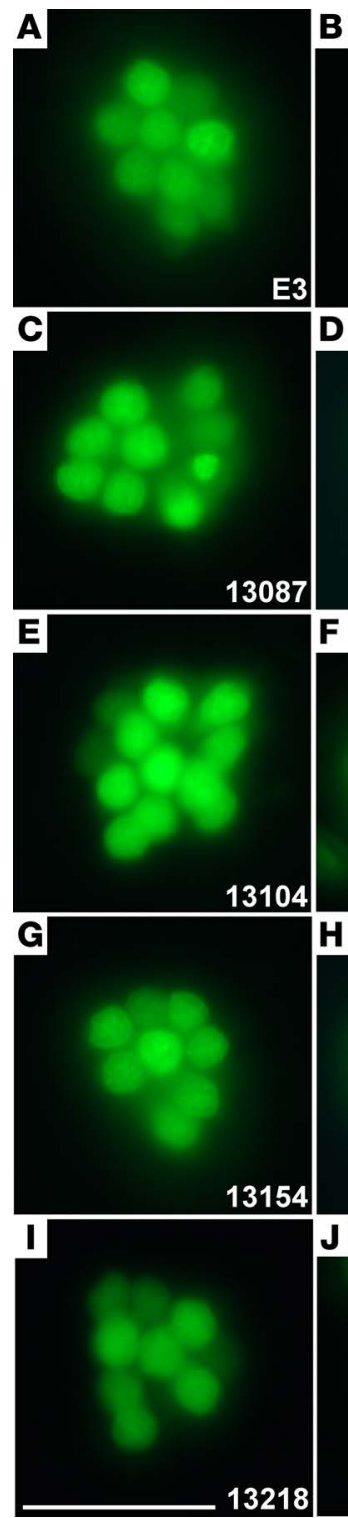
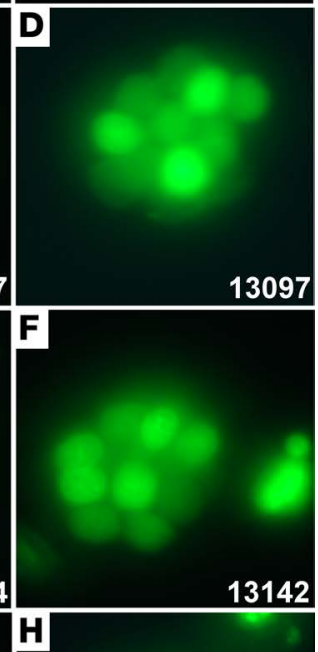

B
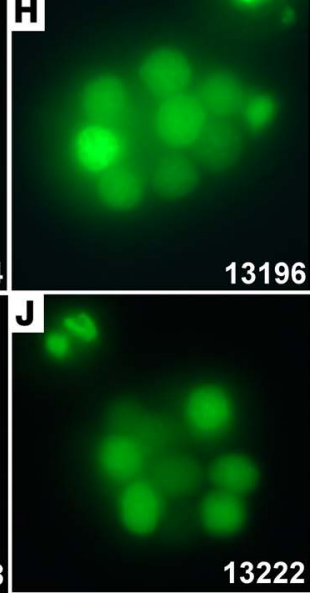

Figure 9. Prevention of gentamicin-induced hair cell loss in zebrafish larvae with otoprotectants at a concentration of $\mathbf{1 0 0} \mu \mathrm{M}$. Zebrafish larvae (4 dpf) were treated for 5 hours with (A) E3 control, (B) $10 \mu \mathrm{M}$ gentamicin, or (C-J) $10 \mu \mathrm{M}$ gentamicin and $100 \mu \mathrm{M}$ of compound as indicated. Neuromasts were prelabeled with $3 \mu \mathrm{M}$ Yo-Pro-1. $n=3$ independent experiments with 3 or more fish per well. Representative images of individual neuromasts shown. Scale bar: $25 \mu \mathrm{m}$.

Details of the 13 compounds that prevented or attenuated gentamicin-induced death of OHCs in mouse cochlear cultures are shown in Figure 10B. All have reached different stages of preclinical and clinical development, and the majority have physicochemical properties that are ideal for oral absorption and potential passage through the blood-labyrinth barrier (37). These include a MW of $<450$ daltons, a cLogP of $<4$, and a polar surface area of $<80 \AA^{2}$. Of the 13 compounds, 4 are known potassium channel blockers, 4 are ionotropic glutamate receptor antagonists, and the other 5 belong to several different classes of agonists or antagonists. The fourth physicochemical property shown in Figure 10 is the $\mathrm{p} K_{\mathrm{a}}$, a value that indicates the $\mathrm{pH}$ at which $50 \%$ of the molecules will be ionized. There is a correlation between $\mathrm{p} K_{\mathrm{a}}$ and the ability of the compound to interact with the MET channel, and all the positively charged compounds ( $\left.\mathrm{p} K_{\mathrm{a}}>8.0\right)$, with the exception of 13196 and 13228, were able to block the MET channel to varying degrees. The other compounds $\left(\mathrm{p} K_{\mathrm{a}}<6.0\right)$ are in a neutral form at physiological $\mathrm{pH}$ and did not block the MET current.

By excluding all compounds that caused significant hair-bundle damage when tested alone at $100 \mu \mathrm{M}$ and by selecting those that protect against $5 \mu \mathrm{M}$ gentamicin at a concentration of $50 \mu \mathrm{M}, 5$ ion-channel inhibitors emerged as lead otoprotectants. These were 13142 [[ \pm -1-(1,2-diphenyl ethyl) piperidine] and 13222 (ifenprodil), NMDA receptor antagonists that also block both the MET current and $I_{\mathrm{K}, \text { neo }}$ in early postnatal mouse cochlear hair cells; two inhibitors of $\mathrm{K}_{\mathrm{v}} 7$ channels (38), 13097 (XE991) and 13143 (linopirdine) $(32,33,39,40)$, both of which block $I_{\mathrm{K}, \text { neo }}$ but not the hair cell MET current; and 13154 , a selective antagonist of the ATP-sensitive $\mathrm{K}^{+}$channel Kir6 that blocks both the hair cell MET current and $I_{\mathrm{K}, \text { neo }}$. While all 5 compounds inhibit $I_{\mathrm{K}, \text { neo }}$, and although the results reveal $\mathrm{K}^{+}$depolarization can provide protection from gentamicin, none of them cause an immediate change in the resting membrane potential of the OHCs, and none of them had an effect on the viability of the hair cells in vitro over the course of 48 hours. It is unlikely, therefore, that interactions between the compounds and $I_{\mathrm{K} \text {,neo }}$ determine their protective properties. The question therefore arises as to how these 5 compounds protect OHCs in mouse cochlear cultures.

Previous studies have indicated that aminoglycosides cause hair cell death by activating NMDA receptors and have shown that the NMDA modulators ifenprodil (13222), dizocilpine, and spermine limit aminoglycoside-induced hair cell loss in both rats and guinea pigs in vivo (41-43). While it has been unclear whether hair cell death is due to a direct effect on hair cells or due to an indirect effect via receptors present on the afferent fibers innervating the hair cells (44), a recent study in zebrafish has shown that excess glutamate signaling through ionotropic glutamate receptors induces hair cell death irrespective of the presence or absence of nerve fibers (45). Compounds 13142 and 13222 may therefore prevent aminoglycoside-induced hair cell death by blocking $\mathrm{Ca}^{2+}$ entry into hair cells via NMDA receptors $(41,42,46)$. Although 13142 and 13222 also block the hair cell MET channel and may therefore additionally provide protection by limiting aminoglycoside antibiotic entry, neither caused a significant reduction in GTTR loading, suggesting they either have a low affinity for the MET channel relative to GTTR or exert their otoprotective effects through the NMDA receptor.

Of the remaining 3 compounds (13097, 13143, and 13154), compound 13143 (linopirdine) is the only one that reduces GTTR labeling. While this may explain why it provides protection, 13143 does not block the MET channel, suggesting its effects on GTTR loading are indirect. Compound 13097 (XE991) does not block the MET current or reduce GTTR labeling, suggesting that it acts downstream of aminoglycoside entry. Although compound 13154 does block the MET channel, it does not reduce GTTR labeling, suggesting that it also acts downstream of aminoglycoside entry. As linopirdine and XE991 are known to block KCNQ4, a channel required for the survival of mature OHCs $(47,48)$, and as the perfusion of linopirdine 
A

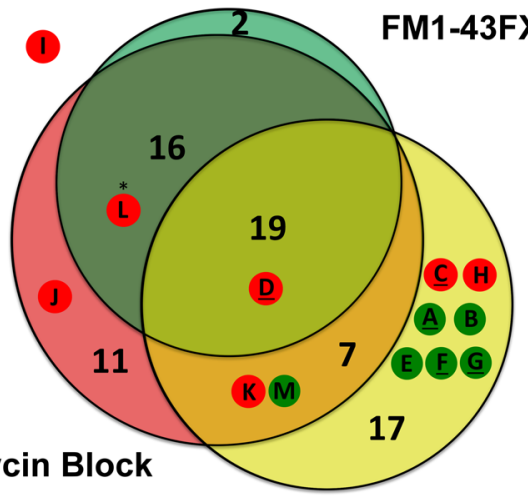

Blocks the MET channel

Does not block the MET channel

*

Loss of viability in fish after one

hour (not scored in the neomycin protection assay

TR-Neomycin Block

Neomycin Protection

B

\begin{tabular}{|c|c|c|c|c|c|c|c|c|}
\hline VENN & $\begin{array}{c}\text { Compound } \\
\text { Number }\end{array}$ & Structure & $\begin{array}{c}\text { Commercial } \\
\text { Name }\end{array}$ & $\begin{array}{l}\text { Biological } \\
\text { Activity }\end{array}$ & MW & CLogP (CLogD) & PSA & pKa \\
\hline$\underline{\mathbf{A}}$ & $\underline{\text { UoS-13154 }}$ & & PNU 37883 & $\begin{array}{l}\text { Selective } \mathrm{K}_{\text {ir }} 6 \\
\text { (KATP) channel } \\
\text { antagonist }\end{array}$ & 345 & $\begin{array}{c}3.48 \\
(1.06)\end{array}$ & 37 & 12.47 \\
\hline B & UoS-13087 & OS $^{\mathrm{N}} \mathrm{O}$ & AM 92016 & $\begin{array}{l}\text { KV channel } \\
\text { blocker }\end{array}$ & 447 & $\begin{array}{c}2.69 \\
(1.54)\end{array}$ & 79 & 8.63 \\
\hline$\underline{c}$ & UoS-13097 & & XE-991 & $\begin{array}{c}\text { Selective } \mathrm{Kv}_{\mathrm{v}} \\
\text { (KCNQ) channel } \\
\text { blocker }\end{array}$ & 376 & $\begin{array}{c}4.86 \\
(4.85)\end{array}$ & 43 & 5.77 \\
\hline$\underline{\mathbf{D}}$ & $\underline{\text { UoS-13143 }}$ & & Linopirdine & $\begin{array}{c}\text { Kv7 (KCNO) } \\
\text { channel blocker }\end{array}$ & 391 & $\begin{array}{c}4.41 \\
(4.41)\end{array}$ & 46 & 5.35 \\
\hline E & UoS-13104 & & Ro 04-5595 & $\begin{array}{c}\text { GluN2B } \\
\text { antagonist }\end{array}$ & 332 & $\begin{array}{c}4.61 \\
(3.85)\end{array}$ & 33 & 8.08 \\
\hline$\underline{F}$ & UoS-13142 & & $\begin{array}{c}( \pm)-1-(1,2- \\
\text { Diphenylethyl) } \\
\text { piperidine }\end{array}$ & $\begin{array}{l}\text { NMDA channel } \\
\text { blocker }\end{array}$ & 265 & $\begin{array}{c}4.84 \\
(2.24)\end{array}$ & 3.2 & 10.05 \\
\hline$\underline{\mathbf{G}}$ & UoS-13222 & & Ifenprodil & $\begin{array}{c}\text { GluN2B negative } \\
\text { allosteric } \\
\text { modulator }\end{array}$ & 325 & $\begin{array}{l}3.57 \\
(2.3)\end{array}$ & 44 & 9.03 \\
\hline $\mathrm{H}$ & UoS-13190 & & SYM 2206 & $\begin{array}{l}\text { AMPA negative } \\
\text { allosteric } \\
\text { modulator }\end{array}$ & 366 & $\begin{array}{c}2.81 \\
(2.81)\end{array}$ & 89 & 3.35 \\
\hline 1 & UoS-13150 & & FPL 64176 & $\begin{array}{l}\text { L-type Ca2+ } \\
\text { channel } \\
\text { activator }\end{array}$ & 347 & $\begin{array}{c}5.01 \\
(5.01)\end{array}$ & 59 & - \\
\hline $\mathrm{J}$ & UoS-13170 & & ZK 93423 & $\begin{array}{c}\mathrm{GABA}_{\mathrm{A}} \text { receptor } \\
\text { antagonist }\end{array}$ & 390 & $\begin{array}{c}3.86 \\
(3.86)\end{array}$ & 73 & - \\
\hline $\mathrm{k}$ & Uos-13196 & & $\begin{array}{l}\text { m- } \\
\text { chlorophenylbi } \\
\text { guanide }\end{array}$ & $\begin{array}{c}5-\mathrm{HT}_{3} \text { receptor } \\
\text { agonist }\end{array}$ & 211 & $\begin{array}{c}1.33 \\
(-1.65)\end{array}$ & 98 & 10.15 \\
\hline L & UoS-13228 & & 2-APB & $\begin{array}{c}\mathrm{IP}_{3} \text { receptor } \\
\text { antagonist }\end{array}$ & 225 & $\begin{array}{c}3.71 \\
(1.62)\end{array}$ & 35 & 9.5 \\
\hline M & UoS-13218 & & MR 16728 & $\begin{array}{l}\text { Stimulates } \\
\text { acetylcholine } \\
\text { release }\end{array}$ & 356 & $\begin{array}{c}4.55 \\
(2.30)\end{array}$ & 32 & 9.67 \\
\hline
\end{tabular}

Figure 10. Summary of results and properties of compounds providing protection in mouse OHCs. (A) Proportional Venn diagram showing the number of compounds effective in the 3 zebrafish assays, with small circles identifying the compounds in each sector that were effective in the mouse OHCs. The 5 lead compounds are underlined. (B) Corresponding Venn numbers, identifier numbers, structure, commercial name, and known biological activity of the 13 compounds found to protect mouse $\mathrm{OHCs}$ from gentamicin-induced damage at $50 \mu \mathrm{M}$. MW, a measure of lipophilicity (cLogP and cLogD), polar surface area (PSA), and $p \mathrm{~K}_{\mathrm{a}}$ ( $\mathrm{pH}$ at which the compound is 50\% ionized) for compounds are also included. Thick black lines separate compounds of differing biological activity. 
into the inner ear leads to the loss of cochlear OHCs (49), these compounds would require modification to provide otoprotectants for use in mature animals. KCNQ4 is not, however, expressed in early postnatal hair cells (35), and XE991 protects at a concentration below its $\mathrm{IC}_{50}$ for KCNQ4 in mature inner hair cells, which is estimated to be $30 \mathrm{nM}$ (assuming a Hill coefficient of 1) (50), providing further evidence it is acting downstream of aminoglycoside entry.

The results identify 5 lead compounds that can be used to inform the development of drugs for protecting sensory hair cells in the mammalian inner ear from the toxic side effects of the aminoglycoside antibiotics. This more than doubles the number already identified as being wholly or partially effective in mouse hair cells using a similar approach, i.e., preselection using zebrafish lateral line neuromasts (16-23), proving the value of this strategy and providing additional reagents that will help solve an ever-increasing clinical issue.

\section{Methods}

\section{Compound library}

A Tocriscreen Custom Collection Ion Channel Set of 160 biologically active compounds (ion-channel activators and inhibitors supplied predissolved as $10 \mathrm{mM}$ stock solutions in DMSO) was obtained from Tocris. Molecules effective in one or more of the initial screens were confirmed by testing new stocks from Tocris, HelloBio, and MilliporeSigma. Purity was $>95 \%$, and compounds were used without further purification. Physicochemical properties were calculated using MarvinSketch 16.8.15.0 by ChemAxon (https://www.chemaxon.com). Chemical structures were drawn using ChemDraw Prime 15.0.

\section{Zebrafish assays}

Zebrafish embryos were obtained from sibling crosses of adult nacre ( ifta $^{-/-}$) fish (51) either housed at or obtained from the University of Sheffield. The nacre strain has reduced numbers of pigmented melanophores and was used for the screens involving fluorescent compounds, as levels of pigmentation are substantially reduced and signal detection is thus improved. The development of lateral line neuromasts and hair cells in this strain appears normal (for examples, see Figure 1A and Supplemental Figure 1). Larvae at $4 \mathrm{dpf}$ were dispensed into 96-well microtiter plates at a density of 3-4 per well. For the FM 1-43 dye-loading assay, larvae were incubated in $100 \mu \mathrm{M}$ compound (total volume of $100 \mu \mathrm{l}$ ) at room temperature for 10 minutes, exposed to $3 \mu \mathrm{M}$ FM 1-43FX (Life Sciences, F35355) for 1 minute, washed, and then anesthetized with $0.025 \%$ MS222 (MilliporeSigma E10521). Wells containing larvae were imaged at $\times 4$ magnification using the Phenosight imaging system (Ash Biotech), and larvae were scored for presence or absence of fluorescently labeled neuromasts. If the larvae only had a small proportion of neuromasts (e.g., only 3 terminal neuromasts or just the head neuromasts, see Figure 1A) labeled, the compound was described as a weak blocker. A compound was considered toxic if there was loss of viability or the fish became fluorescent and neuromasts could not be detected above background (Figure 1C). For the TR-Neo screen, larvae were incubated in $100 \mu \mathrm{M}$ compound and exposed to $25 \mu \mathrm{M}$ TR-Neo for 90 seconds, washed, and anesthetized. Entire larvae were imaged and scored for presence or absence of labeled neuromasts with a $\times 16$ objective on a Zeiss IM-35 inverted microscope. The trunk neuromasts 3-9 were assayed for presence or absence of fluorescence with a $\times 40$ objective. A compound was designated as a weak blocker if fluorescence was only detected at $\times 40$. The neomycin-protection and gentamicin screen were performed as described previously (26). Briefly, Yo-Pro-1 (Invitrogen, Y3603) (29) prelabeled larvae were incubated in $25 \mu \mathrm{M}$ test compound with $6.25 \mu \mathrm{M}$ neomycin sulphate for 1 hour or 50 or $100 \mu \mathrm{M}$ test compound with $10 \mu \mathrm{M}$ gentamicin sulphate (MilliporeSigma, G3632) for 5 hours. Plates were screened using a $\times 16$ objective. Trunk neuromasts 3-9 were viewed and assessed as described previously (26).

\section{Mouse cochlear culture protection assay}

Mouse pups of either sex were obtained from a colony of outbred CD1 mice that was maintained at the University of Sussex with stock originally obtained from Charles River. Cochlear cultures were prepared from pups at P2 as described previously $(26,52)$ and, after 1 day in vitro, were treated with $50 \mu \mathrm{M}$ test compound and $5 \mu \mathrm{M}$ gentamicin sulphate (MilliporeSigma, G3632) or augmented levels of extracellular $\mathrm{Na}^{+}$or $\mathrm{K}^{+}$and $5 \mu \mathrm{M}$ gentamicin sulphate for a further 48 hours before fixation and staining with TRITC-phalloidin (MilliporeSigma, P1951) or double labeling with Texas red-conjugated phalloidin 
(Invitrogen) and anti-myosin7a (Proteus, 25-6790). Cultures were imaged with a Zeiss Axioplan2 microscope. Compounds that did not provide protection were discarded, and no further tests were run on them. Those providing protection were retested at varying concentrations. For details of the analysis of hair cell survival/protection, see the Supplemental Methods.

\section{Electrophysiology}

MET currents and basolateral potassium currents were recorded from OHCs in cochlear cultures that had been prepared from P2 pups and maintained for 1 or 2 days in vitro as previously described (26). For full details, see the Supplemental Methods.

\section{GTTR-loading assay in mouse cochlear cultures}

Mouse cochlear cultures were treated with $1 \%$ DMSO or $100 \mu \mathrm{M}$ test compound for 5 minutes, GTTR (obtained from P.S. Steyger, Oregon Hearing Research Center, Oregon Health \& Science University, Portland, Oregon, USA) was added to a final concentration of $0.2 \mu \mathrm{M}$ for a further 10 minutes, and cultures were washed 3 times. Images were captured at a fixed distance from the basal end of the explant 10 minutes after the onset of GTTR washout. Each compound was tested on a minimum of 3 different cultures, and a similar number of DMSO controls were included in each experiment. Intensity values were obtained from $40 \times 40$ pixel regions of interest in 10 adjacent first-row OHCs. Analysis was as follows: 10 technical replicates (cells) were nested within 3-5 biological replicates for each compound or the 1\% DMSO control. Background-corrected intensity values were natural logarithm-transformed as $\ln ($ data +1$)$ and analyzed using mixed-effects models, assuming normal error distributions. For full details of analysis, see Statistics.

\section{Statistics}

Electrophysiology. Potassium current activation curve data were analyzed for $\mathrm{V}_{1 / 2}$ and $\mathrm{S}$ by 2-tailed paired $t$ test using Graphpad QuickCalcs online software. $\mathrm{G}_{\max }$ was analyzed by performing a 1-sample $t$ test (2-tailed testing) using GraphPad InStat v3.10, assigning statistical significance at $P<0.05$. For additional information, see the Supplemental Methods.

The GTTR-loading assay in mouse cochlear cultures, the mouse cochlear culture protection assay and antimicrobial susceptibility testing were analyzed using R 3.2.2 (53) with the 'Ime4' package and are detailed below.

GTTR-loading assay in mouse cochlear cultures. GTTR loading was analyzed using mixed-effects models, assuming normal error distributions. The compound applied was fitted as a categorical fixed effect, and the experimental design of hierarchical replication for each compound, grouped by day, was fitted as random effects. Within this modeling framework, each compound was compared with $1 \%$ DMSO control values using 2-tailed $t$ tests, assigning statistical significance at $P<0.05$.

Mouse cochlear culture protection assay. The effects of gentamicin, $\mathrm{NaCl}$, and $\mathrm{KCl}$ on hair cell survival were modeled using generalized linear mixed-effects models, assuming Poisson-distributed errors and log link functions. Explanatory variables were fitted as interacting categorical fixed effects. Variability between replicate measurements on each cochlea, nested within variability between observers, was modeled as random effects. Pairwise comparisons among all combinations of interacting fixed effects were quantified using Tukey honestly significant difference post-hoc tests, assigning statistical significance at $P<0.05$.

Bacterial growth conditions and antimicrobial susceptibility testing. Antimicrobial susceptibility testing was analyzed using mixed-effects models, assuming normal error distributions. $\log _{10}$-transformed luminescence was modeled as the response variable. Compound identity (including compound-free control) was fitted as a single categorical explanatory variable. Technical replication, nested within biological variation, was fitted as random effects. Pairwise contrasts, comparing each compound to the control, were assessed. Adjusted $P$ values were produced using the Benjamini-Hochberg false discovery rate method, assigning statistical significance at $P<0.05$.

\section{Study approval}

Animals were raised as per Home Office guidelines, and all experiments were in accordance with the Home Office Animals (Scientific Procedures) Act 1986 and were performed with approval of the Animal Welfare and Ethical Review Boards at the Universities of Sussex and Sheffield. 


\section{Author contributions}

EJK, NKK, MOR, SRK, DMC, SB, RJG, AS, MD, CJK, and GPR conducted experiments and analyzed data; SRK, JCB, and CJK performed statistical analysis; SEW, SJW, SB, TTW, CJK, and GPR designed the research; MD, SRK, SB, and TTW contributed to the manuscript; and EJK, NKK, MD, CJK, and GPR wrote the manuscript.

\section{Acknowledgments}

This work was supported by the Medical Research Council (MR/K005561/1 to CJK, GPR, and SEW), Action on Hearing Loss (PhD studentship S30 for SRK), and the Biotechnology and Biological Sciences Research Council (BB/M01021X/1 to TTW and SB). The Sheffield Zebrafish Screening Unit was supported by the Medical Research Council (G0802527). All data are provided in the Results section of the paper and in the supplemental material.

Address correspondence to: Corné J. Kros or Guy P. Richardson, Sussex Neuroscience, School of Life Sciences, University of Sussex, Brighton, BN1 9QG, United Kingdom. Phone: 44.1273.678341; Email: c.j.kros@ sussex.ac.uk (C.J. Kros). Phone: 44.1273.678717; Email: g.p.richardson@sussex.ac.uk (G.P. Richardson).

1. Forge A, Schacht J. Aminoglycoside antibiotics. Audiol Neurootol. 2000;5(1):3-22.

2. Huth ME, Ricci AJ, Cheng AG. Mechanisms of aminoglycoside ototoxicity and targets of hair cell protection. Int J Otolaryngol. 2011;2011:937861.

3. Jackson J, Chen C, Buising K. Aminoglycosides: how should we use them in the 21st century? Curr Opin Infect Dis. 2013;26(6):516-525.

4. Xie J, Talaska AE, Schacht J. New developments in aminoglycoside therapy and ototoxicity. Hear Res. 2011;281(1-2):28-37.

5. Cross CP, Liao S, Urdang ZD, Srikanth P, Garinis AC, Steyger PS. Effect of sepsis and systemic inflammatory response syndrome on neonatal hearing screening outcomes following gentamicin exposure. Int J Pediatr Otorhinolaryngol. 2015;79(11):1915-1919.

6. Koo JW, et al. Endotoxemia-mediated inflammation potentiates aminoglycoside-induced ototoxicity. Sci Transl Med. 2015;7(298):298ra118

7. Lange $\mathrm{C}$, et al. Management of patients with multidrug-resistant/extensively drug-resistant tuberculosis in Europe: a TBNET consensus statement. Eur Respir J. 2014;44(1):23-63.

8. Farzal Z, Kou YF, St John R, Shah GB, Mitchell RB. The role of routine hearing screening in children with cystic fibrosis on aminoglycosides: A systematic review. Laryngoscope. 2016;126(1):228-235.

9. Seddon JA, Godfrey-Faussett P, Jacobs K, Ebrahim A, Hesseling AC, Schaaf HS. Hearing loss in patients on treatment for drug-resistant tuberculosis. Eur Respir J. 2012;40(5):1277-1286.

10. Alharazneh A, et al. Functional hair cell mechanotransducer channels are required for aminoglycoside ototoxicity. PLoS One. 2011;6(7):e22347.

11. Kawashima Y, et al. Mechanotransduction in mouse inner ear hair cells requires transmembrane channel-like genes. J Clin Invest. 2011;121(12):4796-4809.

12. Kros CJ, Rüsch A, Richardson GP. Mechano-electrical transducer currents in hair cells of the cultured neonatal mouse cochlea. Proc Biol Sci. 1992;249(1325):185-193.

13. Marcotti W, van Netten SM, Kros CJ. The aminoglycoside antibiotic dihydrostreptomycin rapidly enters mouse outer hair cells through the mechano-electrical transducer channels. J Physiol (Lond). 2005;567(Pt 2):505-521.

14. Vu AA, et al. Integrity and regeneration of mechanotransduction machinery regulate aminoglycoside entry and sensory cell death. PLoS One. 2013;8(1):e54794.

15. Warchol ME. Cellular mechanisms of aminoglycoside ototoxicity. Curr Opin Otolaryngol Head Neck Surg. 2010;18(5):454-458.

16. Ou HC, et al. Identification of FDA-approved drugs and bioactives that protect hair cells in the zebrafish (Danio rerio) lateral line and mouse (Mus musculus) utricle. J Assoc Res Otolaryngol. 2009;10(2):191-203.

17. Chiu LL, Cunningham LL, Raible DW, Rubel EW, Ou HC. Using the zebrafish lateral line to screen for ototoxicity. $J$ Assoc Res Otolaryngol. 2008;9(2):178-190.

18. Hirose Y, Sugahara K, Kanagawa E, Takemoto Y, Hashimoto M, Yamashita H. Quercetin protects against hair cell loss in the zebrafish lateral line and guinea pig cochlea. Hear Res. 2016;342:80-85.

19. Kruger M, Boney R, Ordoobadi AJ, Sommers TF, Trapani JG, Coffin AB. Natural bizbenzoquinoline derivatives protect zebrafish lateral line sensory hair cells from aminoglycoside toxicity. Front Cell Neurosci. 2016;10:83.

20. Ou H, Simon JA, Rubel EW, Raible DW. Screening for chemicals that affect hair cell death and survival in the zebrafish lateral line. Hear Res. 2012;288(1-2):58-66.

21. Owens KN, et al. Identification of genetic and chemical modulators of zebrafish mechanosensory hair cell death. PLoS Genet. 2008;4(2):e1000020.

22. Thomas AJ, Wu P, Raible DW, Rubel EW, Simon JA, Ou HC. Identification of small molecule inhibitors of cisplatin-induced hair cell death: results of a 10,000 compound screen in the zebrafish lateral line. Otol Neurotol. 2015;36(3):519-525.

23. Vlasits AL, Simon JA, Raible DW, Rubel EW, Owens KN. Screen of FDA-approved drug library reveals compounds that protect hair cells from aminoglycosides and cisplatin. Hear Res. 2012;294(1-2):153-165.

24. Gale JE, Marcotti W, Kennedy HJ, Kros CJ, Richardson GP. FM1-43 dye behaves as a permeant blocker of the hair-cell mecha- 
notransducer channel. J Neurosci. 2001;21(18):7013-7025.

25. Majumder P, Moore PA, Richardson GP, Gale JE. Protecting mammalian hair cells from aminoglycoside-toxicity: Assessing phenoxybenzamine's potential. Front Cell Neurosci. 2017;11:94.

26. Kirkwood NK, et al. d-Tubocurarine and berbamine: Alkaloids that are permeant blockers of the hair cell's mechano-electrical transducer channel and protect from aminoglycoside toxicity. Front Cell Neurosci. 2017;11:262.

27. Farris HE, LeBlanc CL, Goswami J, Ricci AJ. Probing the pore of the auditory hair cell mechanotransducer channel in turtle. J Physiol (Lond). 2004;558(Pt 3):769-792.

28. Kindt KS, Finch G, Nicolson T. Kinocilia mediate mechanosensitivity in developing zebrafish hair cells. Dev Cell. 2012;23(2):329-341.

29. Santos F, MacDonald G, Rubel EW, Raible DW. Lateral line hair cell maturation is a determinant of aminoglycoside susceptibility in zebrafish (Danio rerio). Hear Res. 2006;213(1-2):25-33.

30. Baell JB, Holloway GA. New substructure filters for removal of pan assay interference compounds (PAINS) from screening libraries and for their exclusion in bioassays. J Med Chem. 2010;53(7):2719-2740.

31. Connors SP, Gill EW, Terrar DA. Actions and mechanisms of action of novel analogues of sotalol on guinea-pig and rabbit ventricular cells. Br J Pharmacol. 1992;106(4):958-965.

32. Wang HS, et al. KCNQ2 and KCNQ3 potassium channel subunits: molecular correlates of the M-channel. Science. 1998;282(5395):1890-1893.

33. Zaczek R, et al. Two new potent neurotransmitter release enhancers, 10,10-bis(4-pyridinylmethyl)-9(10H)-anthracenone and 10,10-bis(2-fluoro-4-pyridinylmethyl)-9(10H)-anthracenone: comparison to linopirdine. J Pharmacol Exp Ther. 1998;285(2):724-730

34. Humphrey SJ, Ludens JH. K-ATP-blocking diuretic PNU-37883A reduces plasma renin activity in dogs. J Cardiovasc Pharmacol. 1998;31(6):894-903.

35. Marcotti W, Kros CJ. Developmental expression of the potassium current IK, $n$ contributes to maturation of mouse outer hair cells. J Physiol (Lond). 1999;520 Pt 3:653-660.

36. Coffin AB, Rubel EW, Raible DW. Bax, Bc12, and p53 differentially regulate neomycin- and gentamicin-induced hair cell death in the zebrafish lateral line. J Assoc Res Otolaryngol. 2013;14(5):645-659.

37. Rankovic Z. CNS drug design: balancing physicochemical properties for optimal brain exposure. J Med Chem. 2015;58(6):2584-2608.

38. Rogawski MA. Therapeutic potential of excitatory amino acid antagonists: channel blockers and 2,3-benzodiazepines. Trends Pharmacol Sci. 1993;14(9):325-331

39. Schnee ME, Brown BS. Selectivity of linopirdine (DuP 996), a neurotransmitter release enhancer, in blocking voltage-dependent and calcium-activated potassium currents in hippocampal neurons. J Pharmacol Exp Ther. 1998;286(2):709-717.

40. Wang HS, Brown BS, McKinnon D, Cohen IS. Molecular basis for differential sensitivity of KCNQ and I(Ks) channels to the cognitive enhancer XE991. Mol Pharmacol. 2000;57(6):1218-1223.

41. Basile AS, Huang JM, Xie C, Webster D, Berlin C, Skolnick P. N-methyl-D-aspartate antagonists limit aminoglycoside antibiotic-induced hearing loss. Nat Med. 1996;2(12):1338-1343.

42. Han X, et al. Binding of spermine and ifenprodil to a purified, soluble regulatory domain of the N-methyl-D-aspartate receptor. J Neurochem. 2008;107(6):1566-1577.

43. Henley CM. Kanamycin depletes cochlear polyamines in the developing rat. Otolaryngol Head Neck Surg. 1994;110(1):103-109.

44. Kim BY, et al. Effects of memantine on aminoglycoside-induced apoptosis of spiral ganglion cells in guinea pigs. Otolaryngol Head Neck Surg. 2016;155(1):147-154.

45. Sheets L. Excessive activation of ionotropic glutamate receptors induces apoptotic hair-cell death independent of afferent and efferent innervation. Sci Rep. 2017;7:41102.

46. Bieńkowski P, Scińska A, Kostowski W, Koroś E, Kukwa A. [Ototoxic mechanism of aminoglycoside antibiotics--role of glutaminergic NMDA receptors]. Pol Merkur Lekarski. 2000;9(52):713-715.

47. Kharkovets T, et al. KCNQ4, a K+ channel mutated in a form of dominant deafness, is expressed in the inner ear and the central auditory pathway. Proc Natl Acad Sci USA. 2000;97(8):4333-4338.

48. Kros CJ, Ruppersberg JP, Rüsch A. Expression of a potassium current in inner hair cells during development of hearing in mice. Nature. 1998;394(6690):281-284.

49. Nouvian R, Ruel J, Wang J, Guitton MJ, Pujol R, Puel JL. Degeneration of sensory outer hair cells following pharmacological blockade of cochlear KCNQ channels in the adult guinea pig. Eur J Neurosci. 2003;17(12):2553-2562.

50. Oliver D, Knipper M, Derst C, Fakler B. Resting potential and submembrane calcium concentration of inner hair cells in the isolated mouse cochlea are set by KCNQ-type potassium channels. J Neurosci. 2003;23(6):2141-2149.

51. Lister JA, Robertson CP, Lepage T, Johnson SL, Raible DW. nacre encodes a zebrafish microphthalmia-related protein that regulates neural-crest-derived pigment cell fate. Development. 1999;126(17):3757-3767.

52. Russell IJ, Richardson GP. The morphology and physiology of hair cells in organotypic cultures of the mouse cochlea. Hear Res. 1987;31(1):9-24.

53. Pinheiro J, Bates D. Mixed-Effects Models in S and S-PLUS (Statistics and Computing). New York, NY: Springer-Verlag; 2000. 